\title{
Making the Gig Economy Work for Workers: An Exploration of Freelancing Platforms
}

\author{
Juan Carlos Alvarez de la Vega, \\ Northumbria University Social Computing, \\ Newcastle upon Tyne, UK \\ carlos.alvarez@northumbria.ac.uk
}

\begin{abstract}
Freelancing platforms, such as Upwork and Fiverr, have enabled virtual spaces for freelancers to advertise, deliver, and charge for their services worldwide with reduced uncertainty. However, freelancing platforms, like other types of gig work, present challenges for workers such as opaque regulations, ranking systems, and power imbalances that can negatively impact workers' experiences. While research in the gig economy has gained more attention recently, most studies have looked at mainstream platforms, such as Uber, leaving other types of gig work underexplored. Therefore, my PhD will use qualitative and co-design methods to expand the understanding of freelancing platforms' issues and provide design recommendations for improving freelancers' working experiences.
\end{abstract}

Gig economy, Freelancing platforms, Work autonomy, Flexible work

\section{RESEARCH DESCRIPTION}

\subsection{Introduction and Related Work}

The nature of work is rapidly changing due to the growth of platform-mediated work, often referred to as the 'gig economy'. While there is no agreed definition, the gig economy has been broadly described as those markets that use digital platforms for matching customers with service providers on a project or service basis (Donovan, Bradley and Shimabukuro, 2016). Arguably, there are two types of gig economy platforms: locationdependent and online gig work (Woodock and Graham, 2020). The former refers to platforms that mediate work that is contingent on service providers and clients sharing the same location for example, an Uber driver providing ride-hailing services in a particular city. The latter refers to platforms that mediate work occurring entirely online regardless of workers and clients' location for example, a designer in Kenya editing photos for a client in Canada through a freelancing platform like Upwork. Research in $\mathrm{HCl}$, and other disciplines such as economics, has primarily focused on location-dependent platforms, e.g. (Lee et al., 2015; Sutherland and Jarrahi, 2018; Berger et al., 2019), to the point that different media outlets even refer to the gig economy as the ubersiation of work', e.g. (Towers-Clark, 2019). On the other hand, most studies of online gig work have focused on crowdwork platforms, such as Amazon Mechanical Turk, e.g. (Martin et al., 2014; Lascau et al., 2019); yet, freelancing platforms remain seldom studied (Sutherland and Jarrahi, 2018).

Two primary factors shape working conditions in the gig economy. Firstly, companies' guidelines and regulations classify workers as 'independent contractors' who are not employed by platforms but instead use the technology to match with clients (Stefano, 2016). As a result, these independent workers lack crucial benefits usually available in traditional employment, such as paid leave, collective bargaining, anti-discrimination and safety rights (Bajwa et al., 2018). Secondly, gig platforms shape and structure work through technological mechanisms that, in turn, raise unique issues (Sutherland et al., 2019). Examples of these technological mechanisms include customersourced rankings, public profiles, and intrusive surveillance technologies. Studies on the implications of these technologies have revealed negative consequences for workers, such as anxiety, racial and gender biases, and power imbalances (Hannák et al., 2017; Sannon and Cosley, 2019; Shevchuk, Strebkov and Davis, 2019). As the gig economy continues to grow, more research is required to understand its implications.

Freelancing platforms differ from other types of gig work in several respects, surfacing various underexplored issues. Typically, workers in the gig economy have control over their working schedule deciding when to log onto the platforms and carry out work 'on the spot' (Ticona, Mateescu and Rosenblat, 2018). By contrast, freelancing 
platforms require freelancers to remain available for their clients at multiple times of the day, thereby blurring their personal boundaries (Umair, Conboy and Whelan, 2019). Another noticeable difference between freelancing platforms and other types of gig work relates to the control over their clients and wages. Gig economy companies typically use complex algorithms to adjust prices based on the supply of workers and demand for work (Lee et al., 2015). On the other hand, freelancing platforms enable greater autonomy for freelancers to set their pay rates and bid for projects as well as being approached by clients privately. Recent examinations have compared this autonomy to entrepreneurial business ownership, benefitting those freelancers who are highly independent and proactive, while affecting those with lesser sense of entrepreneurship (Nemkova, Demirel and Baines, 2019). Also, studies have highlighted management features freelancing platforms use to manage workers, such as time trackers and work diaries that require further exploration to identify their benefits and consequences (Jarrahi et al., 2020).

My PhD will focus on the following question:

How should freelancing platforms be
enhanced/re-designed to better support
working experiences?

Objectives:

- Investigate freelancing platforms' benefits and challenges for freelancers.

- Explore freelancers' experiences with freelancing platforms.

- Identify design recommendations that would enhance freelancers' experiences on freelancing platforms.

\subsection{Research plan and methods}

My PhD will comprise of three studies. The first exploratory study is underway and aims to investigate freelancing platforms' benefits and challenges through a qualitative analysis of four freelancing communities on the website Reddit (Reddit, no date). The research question for this study is: How do freelancers discuss freelancing platforms on four Reddit communities? Three initial themes have been constructed from this data, which contrast traditional freelance work with platform-specific freelancing experiences. This study starts to unravel freelancing platform issues around work autonomy, transparency, and client relationships. Finding from this study will frame the design of the following two studies.

Work autonomy has been a prominent issue identified in study one. Therefore, study two will aim to explore freelancing platforms mechanisms that structure work autonomy through a researcherdirected diary. This study will examine the research question: How do freelancing platform features that support work autonomy affect working experiences? This study will collect participantgenerated data to explore their interactions and experiences with platform features that structure work autonomy, such as work scheduling, time tracking, and work diaries.

The third study will engage a multidisciplinary group in design workshops to explore the re-design of freelancing platform features for improving working experiences. This study will examine the research question: What design recommendations would enhance the working experience on freelancing platforms? Building on previous findings, participants will be asked to reflect on freelancing platform features and give their views on how re-designing these features can provide an enhanced working experience. The exploration of complex issues, such as client relationships and improved transparency, requires the engagement of a diverse group of freelancers, clients, and freelancing platform stakeholders.

\section{REFERENCES}

Bajwa, U. et al. (2018) 'Towards an understanding of workers ' experiences in the global gig economy', Globalization and Health, 14(124), pp. 2-4.

Berger, T. et al. (2019) 'Uber Happy? Work and Well-being in the "Gig Economy"', Economic Policy, pp. 1-35. doi: 10.1093/epolic/eiz007.

Digital Mindfulness (no date). Available at: https://digitalmindfulness.net (Accessed: 7 June 2020).

Dillahunt, T. R. et al. (2017) 'The Sharing Economy in Computing', Proceedings of the ACM on Human-Computer Interaction. CSCW, 1(CSCW), pp. 1-26. doi: 10.1145/3134673.

Donovan, S. A., Bradley, D. H. and Shimabukuro, J. O. (2016) 'What Does the Gig Economy Mean for Workers?', Congressional Research Service: Report, pp. 1-16. Available at: http://search.ebscohost.com/login.aspx?direct=tr

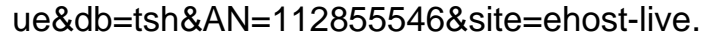

Glasman-Deal, H. (2010) Science Research Writing for Non-Native Speakers of English. London, UK: Imperial College Press.

Hannák, A. et al. (2017) 'Bias in Online freelance marketplaces: Evidence from TaskRabbit and Fiverr', Proceedings of the ACM Conference on Computer Supported Cooperative Work, CSCW, pp. 1914-1933. doi: 10.1145/2998181.2998327.

IFRC (2017) The Future Red Cross and Red Crescent: Futures Exhibition. Available at: https://media.ifrc.org/innovation/solferino- 
academy/the-future-is-now/ (Accessed: 7 June 2020).

International Federation of Red Cross and Red Crescent Societies (2020). Available at: https://www.ifrc.org/en/who-we-are/ (Accessed: 7 June 2020).

Jarrahi, M. H. et al. (2020) 'Platformic Management, Boundary Resources for Gig Work, and Worker Autonomy', Computer Supported Cooperative Work (CSCW), 29(1-2), pp. 153-189. doi: 10.1007/s10606-019-09368-7.

Lambton-Howard, D. et al. (2019) 'Whatfutures: Designing large-scale engagements on Whatsapp', Conference on Human Factors in Computing Systems - Proceedings, pp. 1-14. doi: 10.1145/3290605.3300389.

Lascau, L. et al. (2019) 'Monotasking or multitasking: Designing for crowdworkers' preferences', in Conference on Human Factors in Computing Systems - Proceedings. ACM. doi: 10.1145/3290605.3300649.

Lee, M. K. et al. (2015) 'Working with machines: The impact of algorithmic and data-driven management on human workers', Conference on Human Factors in Computing Systems Proceedings, 2015-April, pp. 1603-1612. doi: 10.1145/2702123.2702548.

Martin, D. et al. (2014) 'Being a turker', Proceedings of the ACM Conference on Computer Supported Cooperative Work, CSCW, pp. 224-235. doi: 10.1145/2531602.2531663.

Nemkova, E., Demirel, P. and Baines, L. (2019) 'In search of meaningful work on digital freelancing platforms: the case of design professionals', New Technology, Work and Employment, 34(3), pp. 226-243. doi: 10.1111/ntwe.12148.

Rainey, J. et al. (2020) 'TalkFutures: Supporting Qualitative Practices in Distributed Community Engagements', in ACM (ed.) Designing Interactive Systems. Eindhoven, Netherlands. doi: https://doi.org/10.1145/3357236.3395531.

Reddit, I. (no date) Reddit, Inc. Available at: https://www.redditinc.com (Accessed: 15 November 2019).

Sannon, S. and Cosley, D. (2019) 'Privacy, power, and invisible labor on Amazon Mechanical Turk',
Conference on Human Factors in Computing Systems - Proceedings, pp. 1-12. doi: 10.1145/3290605.3300512.

Shevchuk, A., Strebkov, D. and Davis, S. N. (2019) 'The Autonomy Paradox: How Night Work Undermines Subjective Well-Being of InternetBased Freelancers', ILR Review, 72(1), pp. 75100. doi: 10.1177/0019793918767114.

Stefano, V. de (2016) The rise of the 'just-in-time workforce': On-demand work, crowdwork and labour protection in the 'gig economy', Publications of the International Labour Office. Geneva, Switzerland.

Sutherland, W. et al. (2019) 'Work Precarity and Gig Literacies in Online Freelancing', Work, Employment and Society, (October). doi: 10.1177/0950017019886511.

Sutherland, W. and Jarrahi, M. H. (2018) 'The sharing economy and digital platforms: A review and research agenda', International Journal of Information Management. Elsevier, 43(February), pp. 328-341. doi: 10.1016/j.ijinfomgt.2018.07.004.

Ticona, J., Mateescu, A. and Rosenblat, A. (2018) Beyond Disruption How Tech Shapes Labor Across Domestic Work \& Ridehailing. Available at: https://datasociety.net/output/beyonddisruption/.

Towers-Clark, C. (2019) The Uberization Of Work: Pros And Cons Of The Gig Economy. Available at:

https://www.forbes.com/sites/charlestowersclark/ 2019/07/08/the-uberization-of-work-pros-andcons-of-the-gig-economyl (Accessed: 20 May 2020).

Umair, A., Conboy, K. and Whelan, E. (2019) 'Understanding the Influence of Technostress on Workers ' Job Satisfaction in Gig-Economy : an', Proceedings of the 27th European Conference on Information Systems (ECIS), Stockholm \& Uppsala, Sweden, June 8-14, 2019. ISBN 978-17336325-0-8 Research-in-Progress, pp. 0-12.

Woodock, J. and Graham, M. (2020) The Gig Economy: A Critical Introduction. 1st edn. Cambridge, UK: Polity Press. 